\title{
Factors contributing to nursing distance education student success
}

\author{
Adrian P. Dacanay, ${ }^{*}$ Stephanie Vaughn, Marsha Orr, JoAnne Andre, Katy Mort \\ School of Nursing, California State University, Fullerton, Fullerton, California, United States
}

Received: September 2, 2014

Accepted: November 2, 2014 Online Published: November 13, 2014

DOI: $10.5430 /$ jnep.v5n2p34

URL: http://dx.doi.org/10.5430/jnep.v5n2p34

\begin{abstract}
Much of the literature has focused on students in the traditional baccalaureate programs versus those who attend classes at a satellite campus and use a hybrid (combination of classroom and on-line) format. In addition, the RN-BSN nursing distance education (NDE) student population is characteristically older than the traditional student, has full or part time nursing employment, and has family responsibilities placing them at higher risk for attrition. Student attrition at a Southern California state university was higher than in the on-campus face-to-face cohorts. As attrition of NDE students continued to be an issue, the identification of risk factors for attrition and development of additional evidence-based interventions and tools was needed to promote optimal student success. Prior to the study, a few informal initiatives had been undertaken to attempt to impact attrition, but with limited success. The study validated and expanded upon reports about non-traditional NDE students at risk of attrition. As a result of the study, more focused retention initiatives have been developed to assist students to be successful and persist to graduation, such as writing tutors, library orientation, computer and technology "boot camps", alternate study plans (full-time and part-time), offering a hybrid course format (on campus and on-line class), and peer support. Attrition of students in the RN-to-BSN cohort has been reduced and the effect of the interventions continues to be monitored.
\end{abstract}

Key Words: Distance education, Student retention, Student success, Nursing education

\section{Introduction}

Distance online education (synchronous and asynchronous) revolutionized education in the last decade and assists students to achieve their academic goals outside of the traditional classroom setting. Online learning has allowed students to earn a degree without ever setting foot onto a university campus. A Southern California university's School of Nursing (SON) initiated a Nursing Distance Education (NDE) program in 2000 employing both on-line and interactive-televised course delivery. The interactive broadcasts were delivered in the hospital classrooms, which not only facilitated BSN education for RNs who worked in the organization, but also fostered access for other RNs in the community While this instructional format provided sev- eral benefits and was convenient, it was not immune to student attrition. As technology advanced, so did the delivery methodologies used in the NDE program. Currently, courses are offered primarily asynchronously online.

The RN to BSN student population in the NDE program is characteristically older than the traditional student, is employed full or part-time, and has family responsibilities, which makes them at higher risk for attrition. The student population is ethnically diverse, with self-reported statistics as follows: $33.3 \%$ Asian/Pacific Islander; 12.8\% Black, 20.5\% Hispanic, $10.2 \%$ Caucasian, and $7.7 \%$ mixed heritage $(15.4 \%$ of the population declined to identify ethnic membership). Although varied retention initiatives had been implemented, RN to BSN NDE student attrition contin-

\footnotetext{
*Correspondence: Adrian P. Dacanay; Email: addacanay@fullerton.edu; Address: School of Nursing, California State University, Fullerton, Fullerton, California, United States.
} 
ues to be higher than that of their on-campus counterparts, which warranted further examination of the factors impacting retention and persistence to graduation.

\section{Background}

Student attrition is defined in several ways, such as a loss of students for nonacademic reasons (e.g. family illness, financial, or health), for academic issues (course failure) and for involuntary reasons such as dismissal. ${ }^{[1]}$ Attrition also includes "stop outs", those who begin a program, leave for a period of time and return, and "stay outs", those who leave a program and do not return, as well as "transfer outs", those individuals who go onto other academic settings, as attributes of attrition. ${ }^{[2-5]}$ These varied definitions of terms may lead to statistics that are not truly comparable. ${ }^{[4]}$ Rosenberg et al. ${ }^{[6]}$ highlighted other issues that influenced student attrition such as personal events, program demands, and environmental factors, such as physical isolation. Retention, defined as continuous enrollment from one term to the next, and persistence, the tracking of the student's progression from admission to graduation, were two benchmark indicators used by several universities to evaluate program outcomes.

Studies conducted in the last five years about students enrolled in online learning have provided more insights regarding the possible reasons for student persistence or attrition in this educational format. ${ }^{[7,8]}$ Time, academic rigor, classification as a "non-traditional student" (enrolled students who are chronologically older than the typical college student population, as well varying levels of education completed $)^{[9]}$ and support systems were some of the significant factors that played a role in student success or lack thereof.

Hyllegard, Deng, and Hunter ${ }^{[10]}$ investigated the extracurricular factors involved in the success of students enrolled in online courses at the community college level. Their descriptive study discovered that a majority of the respondents cited time and personal issues as the primary factors for discontinuing their individual courses. The class workload was also another consistent theme among those surveyed, stating that they did not expect the requirements to be as intensive as they experienced. Although many of the respondents made an effort to keep up, they were unable to continue due to the aforementioned reasons. Social support, or lack of, was also cited as a major factor among online learners. Students were more likely to drop out of their classes if they did not feel supported by their families, their organization or workplace, or a combination of both. ${ }^{[7,10]}$ These studies cited consistent findings of lack of time, lack of support, and the required workload as influencing the students' decision to persist or drop out of courses.

The Institute of Medicine (IOM) ${ }^{[13]}$ Future of Nursing initiative in 2010 called for $80 \%$ of RNs to have a BSN by 2020. The predominant educational level or preparation of nurses in California is an Associate Degree. The RN to BSN NDE program was designed to foster greater access to BSN education for Associate Degree Nursing (ADN) nurses who were unable to attend traditional campus-based programs in California. The SON established partnerships with healthcare organizations throughout California, including organizations in rural and regional areas to increase the number of $\mathrm{BSN}$ prepared nurses by structuring the program in a manner that decreased the perceived barriers to attendance. A systematic review by Du et al. ${ }^{[12]}$ found that students have elected to enroll in distance education because of its perceived flexibility for time, independent learning, and decentralization of the learning and teaching process. The variety of teaching formats utilized by faculty, such as interactive video-conferencing, web-based applications and discussion boards help students to understand complex material. ${ }^{[9,12-15]}$ The RN-BSN NDE program targets working nurses who could attend part-time evening classes or participate in online learning in pursuit of a BSN. These partnerships have allowed the university SON to bring BSN education either to a distance site or online and subsequently increase the number of BSN graduates in these healthcare organizations and the community as a whole.

Despite some informal interventions over the 5 years prior to the study, NDE RN-to-BSN student attrition continued to be higher than the on-campus student group. Therefore, the purpose of this study was to identify factors that contributed to student success in the Nursing Distance Education (NDE) program at one Southern California state university.

\section{Methods}

\subsection{Sample \& recruitment}

Nursing Distance Education (NDE) students in their third semester of the RN-to-BSN program were recruited from five NDE sites in Southern California for voluntary participation in the study. The third semester was the approximate midpoint of the seven semester study plan. The study was explained to the potential participants at each NDE site. Informed consents were distributed and signed prior to data collection; each student at the site was allowed to opt out of participating, or could withdraw from the study at any point without reprisal. No incentives were offered to the students who participated in the survey.

\subsection{Study design}

The study utilized a descriptive study design. A survey tool was used to collect the following demographic data: gender, age group, and primary languages spoken at home, employment-related information such as experience as a $\mathrm{RN}$, area of employment, shift and hours worked per week, marital status, number of children or relatives in the home, and financial responsibilities. In addition, the survey also gathered information regarding the student's individual per- 
ceptions of available resources, and personal and academic support systems. The second part of the survey tool contained open-ended queries that solicited information regarding the student's perceived facilitators and barriers that influenced the student's retention and persistence within the program. Students completed the survey in approximately 30-45 minutes. No identifiers were used; each survey was coded with a numerical code.

\section{Results}

\subsection{Descriptive statistics}

There were a total of 47 participants in the study, ages ranging from 21 years to 52 years with most of the participants between 29 and 36 years of age. The participant population was comprised of $17 \%$ males $(\mathrm{N}=8)$ and $77 \%$ females $(\mathrm{N}$ $=36) ; 3$ participants did not identify their gender.

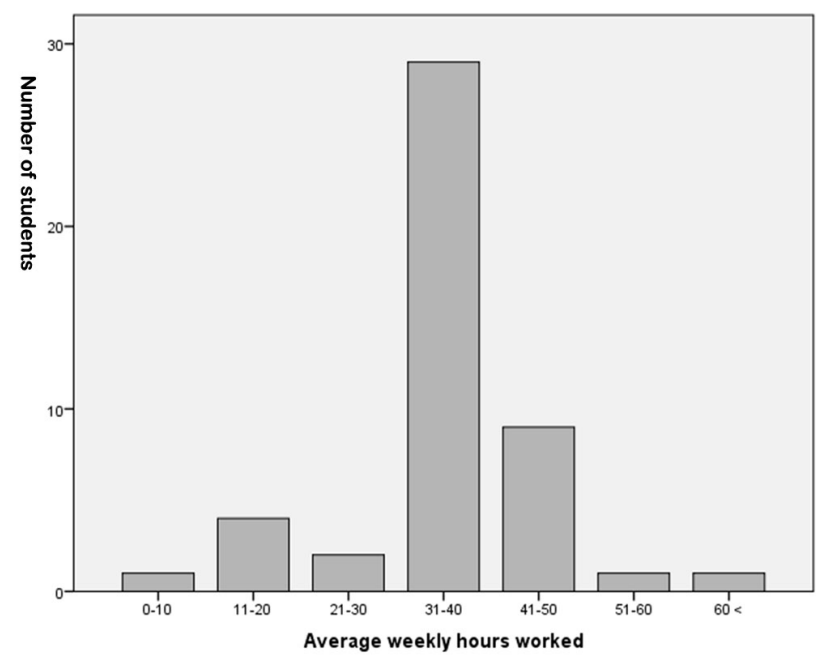

Figure 1: Work Hours per Week

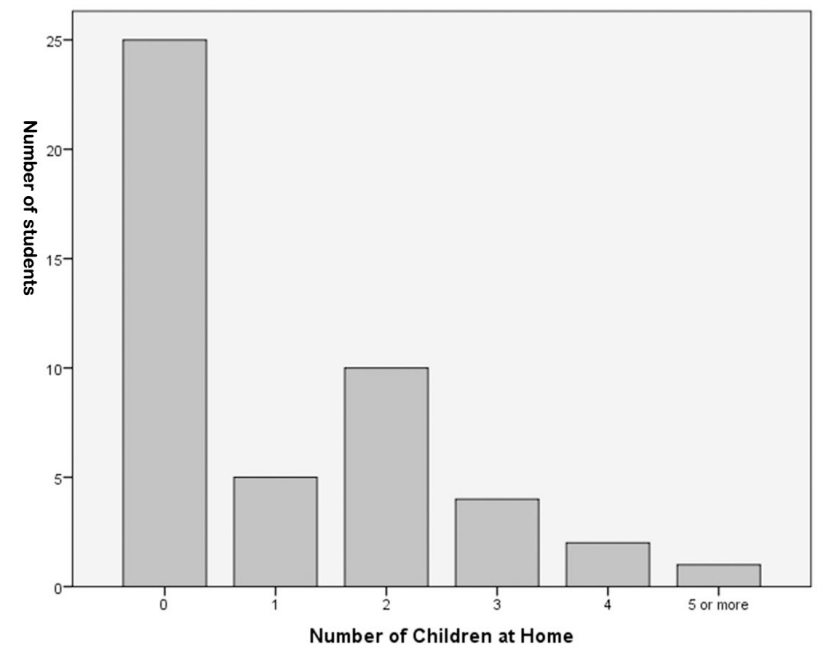

Figure 2: Child Care Responsibilities
Figure 1 highlights the work history of the participants: $62 \%$, worked full-time, averaging about 31-40 hours of work per week, and $24 \%$ worked over 40 hours per week.

Figure 2 shows that 47 percent of all surveyed had at least one or more children at home. Interesting to note was the finding that $36 \%$ of the participants also cared for another adult family member in the home.

\subsection{Open ended queries}

The second part of the instrument was comprised of four open-ended queries (see Table 1).

Table 1: Open-ended queries

Questions:

1) What influenced your decision to return to school for your BSN?

2) What do you perceive, as things that are helping you be successful in the nursing program (e.g. family, school related resources, etc.)?

3) What things either personally, or at work, or at school makes it more challenging for you to attend and be successful in this program?

4) What else could we do as faculty, or as a School of Nursing, to contribute to your success as a NDE student?

These queries solicited responses specific to the influences behind the decision to return to school, reasons for success in the program, perceived challenges faced by each student and recommendations for improvement and success.

\subsection{Thematic analysis}

Thematic analysis of the open-ended query responses yielded extrinsic and intrinsic factors related to attrition and persistence. Extrinsic factors that were identified included perceived need for academic and individualized support from the SON and the need to manage work demands and family responsibilities. One participant revealed that "family support and encouragement and carpooling with a friend" had assisted her to be successful in the program thus far. She also cited the use of "disabilities software to help with typing" as an academic support. "Family support, instructor availability, and mentors at work have really helped me in my pursuit of a BSN", related another participant. One participant reported, "Work is hectic, I feel so exhausted, I cannot even think about school sometimes." "My work is stressful and I sometimes am unable to get off the night (shift) before class the next day," related another. Work demands and other employer associated responsibilities, such as committee work added to the category of extrinsic factors influencing persistence and retention.

Intrinsic factors revealed were personal goals, professional goals, and role stress. Regarding role stress, the participants revealed stressors related to their multiple roles that 
included being a student, breadwinner, and primary family caregiver and these multiple roles added to the personal pressures that they felt. The participants' personal goals ran the gamut; some of the responses were, "It is an opportunity for advancement", "it gets me a step closer to a MSN program," and "it is a lifelong personal goal." Participants had a specific objective in mind that prompted each of them to pursue a BSN. The respondents' personal goals were also related to professional goals, such as moving up the career ladder, or qualifying for a management level position in their individual organizations. Role stress as students was most often related to the rigor of the academic requirements. Participants commented that they would like faculty to "be more flexible with deadlines", and that they felt that the program was "very time-consuming for a PT (part-time) program". Participants shared, "It is difficult to work enough hours and make enough time for assignments; "Financial stressors were related to paying bills, tuition, and family expenses. "school restricts me from picking up extra shifts to help with tuition fees", and "the cost of attendance (in BSN program) is catching up with my savings account"! For some respondents, multiple stressors, financial, family, professional, and student roles, was evident. One related, "It is a challenge for me to work full-time, take care of my family, and attend school at the same time."

\section{Discussion}

Nontraditional students have been identified as higher risk for attrition. ${ }^{[9,12,14,15]}$ They are older, ethnically diverse, and enter college with various abilities and responsibilities (work and family), and therefore, they select distance. The same reasons (familial and financial responsibilities and access to education) have been noted in the literature to prompt applicants to select distance-learning opportunities. The descriptive survey yielded data regarding the various elements that created stress and also that contributed to the success of NDE students. Notable demographic factors were the number of children and/or persons per household and fulltime employment status. Full-time employment consisted of anywhere between 31-40 hours per week and 24\% worked over 40 hours per week. This study's findings are consistent with what was found in the literature. ${ }^{[2,7,9-12]}$ The thematic analysis showed a variety of intrinsic and extrinsic factors that affected students' persistence/retention or attrition in the program. Notable extrinsic factors yielded were perceived support or lack of support at the university and work related demands. The participants described faculty support as consistent feedback regarding assignments, flexibility of courses, writing assistance, and organization of the courses. The participants also felt that they needed additional accessible support such as individualized writing assistance and opportunities to feel more connected to the university. Several related that although they enjoyed the convenience of the satellite campus and the on-line classes, but often felt disconnected from the university and the SON.

Work demands, an extrinsic factor, meant working overtime/extra or night shift hours, being on-call on a regular basis, or other extra involvement related to their individual places of employment. The participants stated that a source of professional role stress came from their place of employment, whereby the management required them to earn higher degrees to be able to advance up the career ladder, and in some cases, to maintain employment in the hospital. Career ladder positions at many hospitals require a BSN as a qualification to for upper levels of advancement. The factors cited by participants in this study are consistent with those found in the literature. Lee, Choi, and $\mathrm{Kim}^{[7]}$ identified five specific factors that affected persistence and attrition among students who were taking distance courses. These were (a) support from work and family; (b) academic locus of control; (c) academic self-efficacy; (d) time management; (e) supportive environment.

Intrinsic factors were personal and professional goals and perceived role stress. Personal and professional goals were consistently evident in the findings; personal goals were to further their education and to earn advanced degrees and/or certifications in the future. Professional goals also referred to earning advanced degrees to advance in the nursing profession, as well as compliance with hospital-mandated requirements for employment. Many healthcare organizations strongly recommend or mandate that staff nurses pursue their BSNs, especially those that are pursuing Magnet recognition.

Role stress was another intrinsic factor that affected attrition and persistence within the program. The participants experienced stress simultaneous at several levels: student, personal, financial, and professional. They felt stress as students in keeping up with assignments and coursework to maintain their GPA and stay in the program. Some participants who were returning to school after several years had to re-acclimate to the student role and learn how to balance coursework with work hours. Personal stress stemmed from the multiple roles of being parents, spouses, caregivers, or all of these. Financial stressors referred to the need to be able to pay their individual and/or family expenses, and sometimes from being the sole financial provider for their family.

\section{Implications \& recommendations}

The non-traditional RN-to-BSN student population in this university's NDE program is at higher risk for attrition related to age, family responsibilities, and work commitments. Even though the participants noted the presence of support from the SON, it was apparent that additional retention strategies and initiatives for the NDE student population were needed. The addition of focused indicators from the data and the development of other evidence-based interventions may promote higher persistence/retention and success 
in the NDE student population. As indicators are identified, the SON will monitor to ensure that the additional initiatives promote the desired student outcomes. Strategies need to be culturally sensitive and tailored to each student's needs as they are identified.

Wu, Low, Liu, Penaar, and $\mathrm{Xia}^{[16]}$ identified 31 critical success strategies essential to the infrastructure of a distancelearning program; pursuant to the study, the SON has instituted a majority of these strategies: (a) web-based learning sites that are stable, reliable, and easy to access via computer, (b) embedded synchronous and asynchronous communication, (c) learning materials that are concise and of high relevance to content, (d) learning materials with wide breadth and high depth in coverage, (e) audio and video capabilities and features to convey and demonstrate concepts, (f) orientation to the course technology via "boot camp" courses, (g) assessment items contain practical components, and have clarity relating to course requirements, (h) webassisted group assessment to encourage teamwork between students, (i) instructors well-versed in the technology, possess strong interactive teaching skills, and provide guidance and structure to the online courses.

As NDE courses are currently offered in various delivery methods, asynchronous and synchronous, as well as faceto-face and an online learning platform at the university (i.e. Moodle), the transition from traditional classroom learning to other modalities in distance instruction can pose challenges for students accustomed to a face-to-face format of teaching. If a student is not computer-savvy or has very little experience with online media, the student may be challenged to stay abreast of coursework in a virtual environment. A focused orientation program to help students transition to the virtual classroom should be considered as an intervention such as a "technology boot camp" to identify and assist students' virtual learning needs and strengths. A study by Gilmore and Lyons ${ }^{[8]}$ found that faculty-designed faceto-face orientation programs effectively reduced the attrition rate of its students in the online program from 20 percent to less than 1 percent during the first 6 weeks of instruction in a BSN program. The "in-person" orientation session allowed students ample time to become familiar with the new technology, connect with peers and faculty members to establish rapport, and have an opportunity to practice and ask questions related to the online classroom environment.

Individualized intervention plans, which included precounseling, an assessment questionnaire prior to the start of the program, an orientation course, and academic support coordinators were found to increase retention in distance education programs, according to a study by Nichols. ${ }^{[15]}$ Park and $\mathrm{Choi}^{[11]}$ found that personal factors differed among distance online learners, and certain factors such as personal support, organizational support, and motivation were associated with the individual student's persistence or attrition. Although trends were identified among the NDE stu- dents, it is important to screen each student early to identify the individual student's needs and to find accessible resources. ${ }^{[9]}$ Personal support is provided by the university SON's mentorship program. This features peer-matched and self-selected mentors, as well as mentors trained specifically to be part of this effort. The mentors provide individualized support and resources to the students in need. In addition, writing tutors are also recruited to assist students in academic writing requirements.

Acknowledgement of risk factors for attrition should always be a part of the discussion on program retention, as well as the development of possible retention interventions. Extrinsic factors that should be considered include, but are not limited to, personal/family concerns, caregiver or family provider considerations, health issues, and financial situation. Risk factors need to be identified early, in order to facilitate early intervention and support. Online and electronic media support availability should also be augmented to accommodate students who are unable to speak with nursing faculty and staff in person, or for those whose work schedules do not allow for that communication. Real-time on-line support via chat rooms, webinar, or virtual conference platforms should be considered as options.

Another strategy needed to promote persistence is writing and library research assistance. Writing assignments and research papers are an integral component of BSN curricula and assist in the development of good written communication skills, which can be challenging for students who have not recently written a major paper. Another obstacle is the lack of skills in finding scholarly sources for information and citation. Allotting time via in-class or via webinar as a dedicated writing and/or library research day for students in the NDE program can decrease the stressor of written assignments. A virtual session with a dedicated librarian to assist students in navigating the library databases can be utilized; as well as small group sessions to work on writing skills. Workload planning and writing workshops were found to be effective strategies in the current literature sources. $^{[1,9,10]}$ These interventions, along with supportive faculty, were associated with increased likelihood of students to "stay on track" and persist with their distance program.

\section{Conclusion}

Technology broke new ground in higher education in the last decade, giving students an option to participate in the virtual classroom through a variety of electronic instruction formats. The BSN NDE program, which includes a satellite classroom close to their home and/or employer, on-line and "hybrid like" course delivery, as well as the face to face course offerings provides flexible and convenient alternative to the traditional classroom format for nurses returning to school, often for the first time in several years, as well as 
those who live and work a distance from a university that offers a BSN program. This southern California state university SON designed the Nursing Distance Education program to serve this population's needs; however, attrition of students-at-risk was a continuing problem. Identification of challenges that the students face and analysis of critical success factors have fostered the development and implemen- tation of additional evidence-based interventions and tools necessary to promote optimal student success which has translated into higher retention/persistence and graduation rates, and students achieving their academic goals.

\section{Conflicts of Interest Disclosure}

The authors have no conflict of interest.

\section{References}

[1] Park CL, Perry B, Edwards M. Minimizing attrition: Strategies for assisting students who are at risk of withdrawal. Innovations in Education \& Teaching International. 2011 Mar; 48(1): 37-47. http://dx.doi.org/10.1080/14703297.2010.543769

[2] Hoyt JE, Winn BA. Understanding retention and college student bodies: Differences between drop-outs, stop-outs, opt-outs, and transfer-outs [Electronic Version]. NASPA Journal. 2004; 41(3): 95417.

[3] Jeffreys MR. Tracking students through program entry, progression, graduation, and licensure: Assessing undergraduate nursing student retention and success (Electronic Version). Nurse Education Today. 2007 Jun; 27(5): 406-419. PMID:16920229 http: //dx.doi.org/10.1016/j.nedt.2006.07.003

[4] Robertson S, Canary C, Orr M, Herberg P, Rutledge D. Factors related to progression and graduation rates for rn-to-bachelor of science in nursing programs: Searching for realistic benchmarks. Journal of Professional Nursing. 2010 Nov; 26(2): 99107. PMID:20304377 http://dx.doi.org/10.1016/j.profn urs. 2009.09.003

[5] Seago J, Spetz J. California's minority majority and the white face of nursing. Journal of Nursing Education. 2005 Dec; 44(12): 555-562. PMID: 16402738

[6] Rosenberg L, Perraud S, Willis L. The value of admission interviews in selecting accelerated second-degree baccalaureate nursing students [Electronic Version]. Educational Innovations. 2007 Sep; 46(9): 413-416.

[7] Lee Y, Choi J, Kim, T. Discriminating factors between completers of and dropouts from online learning courses. British Journal of Educational Technology. 2013 Mar; 44(2): 328-337. http://dx.doi . org $/ 10.1111 / \mathrm{j} .1467-8535.2012 .01306 . \mathrm{x}$

[8] Gilmore M, Lyons EM. NURSING 911: An orientation program to improve retention of online RN-BSN students. Nursing Education
Perspectives. 2012 Jan; 33(1): 45-47. http://dx.doi.org/10. 5480/1536-5026-33.1.45

[9] Harris R, Rosenberg L, Grace O'Rourke M. Addressing the challenges of nursing student attrition. Journal Of Nursing Education [Internet]. (2014), [cited October 24, 2014]; 53(1): 31-37. http://dx.doi.org/10.3928/01484834-20131218-03

[10] Hyllegard D, Heping D, Hunter C. Why do students leave online courses? Attrition in community college distance learning courses. International Journal of Instructional Media. 2008 Oct; 35(4): 429434.

[11] Park JH, Hee JC. Factors influencing adult learners' decision to drop out or persist in online learning. Journal of Educational Technology \& Society. 2009 Sep; 12(4): 207-217.

[12] Du SS, Liu ZZ, Liu SS, Yin HH, Xu G, Zhang, GG, Wang AA. Web-based distance learning for nurse education: a systematic review. International Nursing Review [serial on the Internet]. 2013 Jun; 60(2): 167-177. http://dx.doi.org/10.1111/inr.12015 http:// dx.doi.org/10.1111/inr. 12015

[13] IOM. the future of nursing focus on education [Internet]. Washington DC: The Institute of Medicine; c 2010. Available from: http: //www.iom.edu/ /media/Files/ReportFiles/2010/The-F uture-of-Nursing/NursingEducation2010Brief .pdf

[14] Olinger B. Increasing nursing workforce diversity: Strategies for success. Nurse Educator [Internet]. 2011, Mar; 36(2): 5455. PMID:21330890 http://dx.doi.org/10.1097/NNE.0b013 e31820b4fab

[15] Nichols, M. Student perceptions of support services and the influence of targeted interventions on retention in distance education. Distance Education. 2010 Nov; 31(1): 93-113. http://dx.doi.o $\mathrm{rg} / 10.1080 / 01587911003725048$

[16] Wu P, Low S, Liu J, Pienaar J, Xia B. Critical success factors in distance learning construction programs at Central Queensland University: Students' perspective." J. Professional Issues in Engineering Education and Practice. 2014 Jun. http://dx.doi.org.lib-proxy.fullerton.edu/10.10 61/(ASCE) EI.1943-5541.0000217 